\section{Human Papilloma Virus (HPV) - Related Cancers in Human Immunodeficiency Virus - Infected Women with a History of Cervical Dysplasia}

\author{
Rogg K' ${ }^{1}$, Richter MA² and Robinson WR ${ }^{2 *}$ \\ ${ }^{1}$ University of Rochester School of Medicine, Rochester, New York, USA \\ ${ }^{2}$ Tulane Cancer Center, Tulane University School of Medicine, New Orle- \\ ans, Louisiana, USA
}

\begin{abstract}
Results: 71 subjects were identified with HIV infection, cervical dysplasia and at least ten years' follow up. $17 / 71(24 \%)$ were identified with an HPV-related malignancy. The mean age of those diagnosed with HPV-related malignancy was 39 years. Malignancies included: Cervix-9, Vulva-7, Anal-4, Vagina-3, Urethra/Bladder-2 and Oropharyngeal-3. Eight also had in situ neoplasms: Cervix-4, Vulva-3, and Oropharyngeal-1. Four subjects had 3 separate malignancies and two others had 2 malignancies. Compliance with HAART correlated strongly with immunocompetence, response to therapy, use of patient navigators and survival. $60 / 71(84.5 \%)$ subjects underwent screening mammography, 57/71(80.3\%) underwent colonoscopy, and 67/71 (94.3\%) underwent Pap smear testing. Compliance with screening compared favorably with the general population and overall survival was similar.

Discussion/Conclusion: The long-term incidence and mortality from cancer in women with HIV and cervical dysplasia appears to be comparable to that seen in the general population, with the possible exception of oropharyngeal cancers. Compliance with cancer screening recommendations appears to be higher than in the general population. This suggests that structured primary care programs for HIV-infected women are effective in prevention/early diagnosis of cancer. Standardized screening programs for oropharyngeal cancers should be considered in this population.
\end{abstract}

\section{Introduction}

Cancer is one of the leading causes of death in people with HIV/ AIDS $[1,2]$. With the introduction of Highly Active Anti-Retroviral Therapy (HAART) in the mid-1990s, the overall incidence and mortality of cancer has decreased in this population, largely due to striking declines in AIDS-defining cancers such as Kaposi sarcoma and Non-Hodgkin lymphoma [3]. However, the incidence of invasive cervical carcinoma, (also an AIDS-defining cancer) has been relatively stable, while a number of non-AIDS defining cancers have increased in incidence (presumably due to the increasing numbers and age of HIV-infected individuals) and now constitute the majority of cancers in this population $[4,5]$. Factors suspected to contribute to increased cancer incidence in HIV-infected persons include HIV viremia, immune deficiency, oncogenic virus co-infection and lifestyle exposures (e.g., tobacco, alcohol) [6-8]. In particular, among individuals with AIDS, a statistically significant elevated risk of Human Papilloma Virus (HPV) - associated cancers has been reported, with the level of risk strongly correlated with increased levels of immune suppression [9].

And although HIV-associated malignancies have been extensively analyzed and reported, the data on cancers in women, with the exception of invasive cervical cancer, has been relatively limited due to an overall paucity of women in study populations [10]. Further, many of these studies involved populations with multiple additional risk factors for cancer in addition to HIV infection, such as intravenous drug users or men who have sex with men [11]. In contrast to earlier reports, which typically included relatively few HIV-infected women, as well as a relatively short follow-up, the goal of this study is to determine the incidence and outcomes of HPV-related genital and non-genital tract malignancies in HIV-infected women with a 
diagnosis of pre-invasive cervical neoplasia (dysplasia) and at least a 10 -year follow-up. Further, as screening programs have been shown to be very effective in reducing the incidence of invasive cervical cancer in HIV-infected women, the secondary goal of this study is to evaluate the degree of compliance with cancer screening recommendations in this cohort [12].

\section{Methods}

As part of a facility-based Quality Improvement (QI) program performed as a part of the accreditation process for the American College of Surgeons-Commission on Cancer (ACS-COC), all HIV-infected women diagnosed with an HPV-associated malignancy between 1995-2008 was identified. HIV testing was and is routinely offered to all subjects presenting to the gynecology clinic at this institution and approximately $97 \%$ agree to be tested. The data sources included standard medical records from the clinic, tumor registries and clinical research trial records. Data collected includes: Demographics, HIV treatment/response, malignancy treatment/response, other healthcare utilization, use of health navigators and compliance. Of note, data regarding multiple subgroups, such as all subjects who tested positive for HIV and all those with cervical dysplasia was lost in 2005 due to Hurricane Katrina. As a result, specific incidence rates cannot be calculated. The data from the study subjects was recoverable because it was separately reported to the ACS-COC, as described above. The data was analyzed using standard statistical tests, and the study was determined to be exempt from IRB review.

\section{Results}

71 subjects were identified with HIV infection, cervical dysplasia and at least ten years' follow up data from a large, inner-city academic gynecology clinic in New Orleans, Louisiana, out of over 6500 tested. $17 / 71(24 \%)$ were identified with an HPV-related malignancy. The mean age of those diagnosed with HPV-related malignancy was 39 years and all were African-American. Invasive malignancies included: Cervix-9, Vulva-7, Anal-4, Vagina-3, Uretha/Bladder-2 and Oropharyngeal-3. Eight additional subjects had in situ neoplasms which included: Cervix-4, Vulva-3 and Oropharyngeal-1. Four subjects had 3 separate malignancies and two others had 2 malignancies correlated strongly with survival. Compliance with HAART correlated strongly with immunocompetence, (as measured by CD4 $>200 / \mu \mathrm{L}$ ) response to anti-malignancy therapy and survival. Further, compliance correlated strongly with the use of patient advocate/navigators (Table 1).

$35 / 71(49 \%)$ participated in federally-sponsored clinical trials, including AIDS Clinical Trial Group (ACTG) 200, ACTG 293, Southwest Oncology Group (SWOG) 8797, Gynecologic Oncology Group (GOG) 154 and GOG 155. 60/71 (84.5\%) subjects underwent screening mammography, 57/71(80.3\%) underwent colonoscopy and 67/71 (94.3\%) underwent Pap smear testing, all in accordance with American Cancer Society (ACS) guidelines. The level of compliance with guideline-based screening compared very favorably with that seen in the general population of New Orleans and Louisian and overall survival at 5 years was similar [13].

\section{Discussion}

In this cohort, the long-term incidence and mortality from HPV-associated cancers in HIV-infected women with a history of cervical dysplasia was comparable to that seen in women with cervical dysplasia in the general population of this area. This appears to be in contrast with previous reports, which found an increased risk of both AIDS-defining and non-AIDS defining cancers in similar populations [14]. A possible explanation for these findings include strong compliance with HAART as seen here, which is known to be protective for both AIDS-defining and non-AIDS defining cancers. Another explanation could be the increased level of compliance with cancer screening recommendations in this group. While HIV-infected patients with cervical dysplasia are at risk for HPV-associated cancers, that risk does not seem to exceed that seen in the general population of this area, which has long been among the highest in the US $[15,16]$. This apparent success in cancer screening is likely due to the work of a well-organized and (relatively) well-funded clinic system for HIV-infected individuals in the New Orleans Metropolitan area. This system has been in existence for over 25 years, makes extensive use of patient advocate/navigators and has been credited with dramatic improvements in multiple health outcomes [17]. This suggests that communities where HIV infection is common will benefit from organized primary care delivery systems, with emphasis on adherence to HAART.

Another possible explanation for the findings reported here is that the baseline characteristics of this group differ from those in prior studies. This study population, while limited in size, was exclusively female and appeared to have both similar levels of personal risk factors and similar demographics to the general population of the area. Prior studies of cancer risks in HIV-infected persons typically comprised a cohort that was predominantly male and included many additional known risk factors for cancer, including high rates of intravenous drug use, alcohol use, smoking and infection with known cancer- causing viruses such as Hepatitis B and $\mathrm{C}$ viruses, (HBV and HCV) in addition to HPV [18].

It is well known that HIV-infected women from the pre-HAART era demonstrated an elevated risk for and mortality from cervical abnormalities and dysplasia [19]. A study by Ellerbrock et al., reported that 1 in 5 HIV-infected women without previous evidence of cervical dysplasia developed biopsy-confirmed cervical squamous intraepithelial lesions [20]. In addition, HIV-infected women with a greater level of immune suppression have an increased risk of persistent HPV infection and progression to cervical dysplasia [21]. Interestingly, a separate study showed that the incidence of cervical dysplasia in HPV-negative, cytology-negative HIV-infected women with CD4 counts greater than $500 / \mu \mathrm{L}$ was comparable to that in HIV-negative women [22]. Massad et al., found that while the risk for an abnormal Pap test was greater in HIV-infected women than seronegative women, once an HIV-infected woman develops an abnormality, her risk for high grade cervical dysplasia was only marginally greater than that of seronegative women [23]. Of importance for patient care, another study of HIV seropositive women from 1994-2001 from the same investigators found the risk of invasive cervical cancer to be indistinguishable from that of the general population when the HIV seropositive women were enrolled in a program of cervical cancer screening and prevention $[24,25]$.

An intriguing finding from the current study is that the long-term incidence of oropharyngeal cancers may be higher than expected. This may be partially explained as a reflection of the overall increase in oral HPV infection and oropharyngeal cancers in recent years [26]. However, understanding of the pathophysiology of HPV is incomplete and may differ in the female genital tract compared to the oropharyngeal tract. Consistent with this, a study by Beachler, et al., found an elevated prevalence of oral HPV in HIV-infected persons after controlling for differences in cigarette smoking and sexual behavior [27]. This unexpected number of oropharyngeal cancers in HIV-infected persons suggests that standardized screening programs for oropharyngeal cancers should be considered. 
Citation: Rogg K, Richter MA, Robinson WR (2018) Human Papilloma Virus (HPV) - Related Cancers in Human Immunodeficiency Virus - Infected Women with a History of Cervical Dysplasia. J AIDS Clin Res Sex Transm Dis 5: 021.

\begin{tabular}{|c|c|c|c|c|c|c|c|c|c|c|c|c|c|c|}
\hline Subjects & Age & Cervix & Vulva & Anal & Vagina & $\begin{array}{l}\begin{array}{l}\text { Urethra/ } \\
\text { bladder }\end{array} \\
\end{array}$ & Oropharyngeal & Cervix IS & Vulva IS & Oro IS & $\begin{array}{c}\text { HAART } \\
\text { Compliance }\end{array}$ & CD4>200 & $\begin{array}{c}\text { Patient } \\
\text { navigator }\end{array}$ & Survival \\
\hline 1 & 45 & $\mathrm{x}$ & $\mathrm{x}$ & & & & $\mathrm{x}$ & & & & & & & 27 \\
\hline 2 & 52 & & $\mathrm{x}$ & & & & & $\mathrm{x}$ & & & $\mathrm{x}$ & $\mathrm{x}$ & $\mathrm{x}$ & N/A \\
\hline 3 & 50 & $\mathrm{x}$ & & $\mathrm{x}$ & & & $\mathrm{x}$ & & $\mathrm{x}$ & & & & & 19 \\
\hline 4 & 34 & $\mathrm{x}$ & $\mathrm{x}$ & & & & & & & $\mathrm{x}$ & $\mathrm{x}$ & $\mathrm{x}$ & $\mathrm{x}$ & $\mathrm{N} / \mathrm{A}$ \\
\hline 5 & 30 & & & $\mathrm{x}$ & & & & $\mathrm{x}$ & & & $\mathrm{x}$ & $\mathrm{x}$ & $\mathrm{x}$ & N/A \\
\hline 6 & 35 & $\mathrm{x}$ & & & & $\mathrm{x}$ & & & & & & & & 21 \\
\hline 7 & 37 & & & & $\mathrm{x}$ & & & $\mathrm{x}$ & & & $\mathrm{x}$ & $\mathrm{x}$ & $\mathrm{x}$ & N/A \\
\hline 8 & 51 & $\mathrm{x}$ & $\mathrm{x}$ & & $\mathrm{x}$ & & & & & & & & & 9 \\
\hline 9 & 29 & & & & $\mathrm{x}$ & & & & & & $\mathrm{x}$ & $\mathrm{x}$ & $\mathrm{x}$ & N/A \\
\hline 10 & 45 & & $\mathrm{x}$ & & & & & & & & $\mathrm{x}$ & $\mathrm{x}$ & $\mathrm{x}$ & N/A \\
\hline 11 & 38 & $\mathrm{x}$ & & & & & $\mathrm{x}$ & & $\mathrm{x}$ & & $\mathrm{x}$ & & & 13 \\
\hline 12 & 33 & $\mathrm{x}$ & & & & & & & & & $\mathrm{x}$ & $\mathrm{x}$ & $\mathrm{x}$ & N/A \\
\hline 13 & 60 & & & $\mathrm{x}$ & & & & $\mathrm{x}$ & & & $\mathrm{x}$ & $\mathrm{x}$ & $\mathrm{x}$ & N/A \\
\hline 14 & 32 & $\mathrm{x}$ & $\mathrm{x}$ & & & $\mathrm{x}$ & & & & & $\mathrm{x}$ & $\mathrm{x}$ & $\mathrm{x}$ & N/A \\
\hline 15 & 30 & & & & & & & & & & $\mathrm{x}$ & $\mathrm{x}$ & $\mathrm{x}$ & N/A \\
\hline 16 & 36 & $\mathrm{x}$ & & $\mathrm{x}$ & & & & & $\mathrm{x}$ & & $\mathrm{x}$ & $\mathrm{x}$ & $\mathrm{x}$ & 28 \\
\hline 17 & 28 & & $\mathrm{x}$ & & & & & & & & & & & 18 \\
\hline
\end{tabular}

Table 1: Characteristics of HIV-infected women with cervical dyplasia and at least one HPV-associated malignancy.

IS= In Situ; Survival in months; N/A= living at time of this analysis

Compliance with cancer screening recommendations in this study group appeared to be higher than in the general population. Although there is limited data on certain cancers in HIV-infected women, prior studies have indicated benefits of screening these patients for cervical cancer, anal cancer, breast cancer and hepatocellular carcinoma [28]. Currently there is insufficient evidence to recommend lung cancer screening for HIV-infected women without other risk factors such as smoking. Although the incidence of lung cancer is elevated in HIV patients, it has also been reported that they have a greater cumulative pack-year smoking history [29].

\section{Conclusion}

The long-term incidence and mortality from cancer in women with HIV and cervical dysplasia in this small cohort appears to be comparable to that seen in the general population, with the possible exception of oropharyngeal cancers. Compliance with cancer screening recommendations appears to be higher than in the general population. This suggests that structured primary care programs for HIV-infected women are effective in prevention/early diagnosis of cancer. Standardized screening programs for oropharyngeal cancers should be considered in this population.

\section{References}

1. Morlat P, Roussillon C, Henard S, Salmon D, Bonnet F, et al. (2014) Causes of death among HIV-infected patients in France in 2010 (national survey): trends since 2000. AIDS 28: 1181-1191.

2. Trickey A, May MT, Vehreschild J, Obel N, Gill MJ, et al. (2016) Cause-Specific Mortality in HIV-Positive Patients Who Survived Ten Years after Starting Antiretroviral Therapy. PLoS One 11: 0160460.

3. Park LS, Tate JP, Sigel K, Rimland D, Crothers K, et al. (2016) Time trends in cancer incidence in persons living with HIV/AIDS in the antiretroviral therapy era: 1997-2012. AIDS 30: 1795-1806.
4. Simard EP, Pfeiffer RM, Engels EA (2011) Cumulative Incidence of Cancer among People with AIDS in the United States. Cancer 117: 1089-1096.

5. Shiels MS, Pfeiffer RM, Gail MH, Hall HI, Li J, et al. (2011) Cancer burden in the HIV-infected population in the United States. J Natl Cancer Inst 103: 753-762.

6. Silverberg MJ, Chao C, Leyden WA, Xu L, Horberg MA, et al. (2011) HIV infection, immunodeficiency, viral replication, and the risk of cancer. Cancer Epidemiol Biomarkers Prev 20: 2551-2559.

7. Riedel DJ, Rositch AF, Redfield RR (2015) Patterns of HIV viremia and viral suppression before diagnosis of non-AIDS-defining cancers in HIV-infected individuals. Infect Agent Cancer 10: 38.

8. Park LS, Hernández-Ramírez RU, Silverberg MJ, Crothers K, Dubrow R (2016) Prevalence of non-HIV cancer risk factors in persons living with HIV/AIDS: A meta-analysis. AIDS 30: 273-291.

9. Engels EA, Biggar RJ, Hall HI, Cross H, Crutchfield A, et al. (2008) Cancer risk in people infected with human immunodeficiency virus in the United States. Int J Cancer 123: 187-194.

10. Chaturvedi AK, Madeleine MM, Biggar RJ, Engels EA (2009) Risk of human papillomavirus-associated cancers among persons with AIDS. J Natl Cancer Inst 101: 1120-1130.

11. Marcus JL, Chao C, Leyden WA, Xu L, Yu J, et al. (2015) Survival among HIV-infected and HIV-uninfected individuals with common non-AIDS-defining cancers. Cancer Epidemiol Biomarkers Prev 24: 1167-1173.

12. Abraham AG, D’Souza G, Jing Y, Gange SJ, Sterling TR, et al. (2013) Invasive cervical cancer risk among HIV-infected women: a North American multicohort collaboration prospective study. J Acquir Immune Defic Syndr 62: 405-413.

13. Louisiana Breast and Cervical Cancer Health Program (2017) Louisiana Breast Cancer Facts. LBCHP, New Orleans, Louisiana, USA

14. Crum-Cianflone N, Hullsiek KH, Marconi V, Weintrob A, Ganesan A, et al. (2009) Trends in the incidence of cancers among HIV-infected persons and the impact of antiretroviral therapy: A 20-year cohort study. AIDS 23: 41-50. 
Citation: Rogg K, Richter MA, Robinson WR (2018) Human Papilloma Virus (HPV) - Related Cancers in Human Immunodeficiency Virus - Infected Women with a History of Cervical Dysplasia. J AIDS Clin Res Sex Transm Dis 5: 021.

15. Wu XC, Maniscalco L, Zhang L, Yi Y, Lefante C, et al. (2018) Cancer Incidence in Louisiana by Census Tract, 2006-2014. LSU Health Sciences Center, New Orleans, USA.

16. Silverberg MJ, Chao C, Leyden WA, Xu L, Tang B, et al. (2009) HIV infection and the risk of cancers with and without a known infectious cause. AIDS 23: 2337-2345.

17. Clark RA, Mirabelli R, Shafe J, Broyles S, Besch L, et al. (2007) The New Orleans HIV outpatient program patient experience with Hurricane Katrina. J La State Med Soc 159: 276.

18. Simard EP, Pfeiffer RM, Engels EA (2010) Spectrum of cancer risk late after AIDS onset in the United States. Arch Intern Med 170: 1337-1345.

19. Adler DH, Wallace M, Bennie T, Abar B, Meiring TL, et al. (2016) Cumulative Impact of HIV and Multiple Concurrent Human Papillomavirus Infections on the Risk of Cervical Dysplasia. Adv Virol 2016: 7310894.

20. Ellerbrock TV, Chiasson MA, Bush TJ, Sun XW, Sawo D, et al. (2000) Incidence of cervical squamous intraepithelial lesions in HIV-Infected women. JAMA 283: 1031-1037.

21. Strickler HD, Burk RD, Fazzari M, Anastos K, Minkoff H, et al. (2005) Natural history and possible reactivation of human papillomavirus in human immunodeficiency virus-positive women. J Natl Cancer Inst 97: 577586.

22. Harris TG, Burk RD, Palefsky JM, Massad LS, Bang JY, et al. (2005) Incidence of cervical squamous intraepithelial lesions associated with HIV serostatus, CD4 cell counts, and human papillomavirus test results. JAMA 293: $1471-1476$
23. Massad LS, Pierce CB, Minkoff H, Watts DH, Darragh TM, et al. (2014) Long term cumulative incidence of cervical intraepithelial neoplasia grade 3 or worse after abnormal cytology: impact of HIV infection. Int J Cancer 134: $1854-1861$

24. Massad LS, Seaberg EC, Watts DH, Hessol NA, Melnick S, et al. (2004) Low incidence of invasive cervical cancer among HIV-infected US women in a prevention program. AIDS 18: 109-113.

25. Robinson WR, Freeman D (2002) Improved outcome of cervical neoplasia in HIV-infected women in the era of highly active antiretroviral therapy. AIDS Patient Care STDS 16: 61-65.

26. Pytynia KB, Dahlstrom KR, Sturgis EM (2014) Epidemiology of HPV-associated oropharyngeal cancer. Oral Oncol 50: 380-386.

27. Beachler DC, Weber KM, Margolick JB, Strickler HD, Cranston RD, et al. (2012) Risk factors for oral infection among a high prevalence population of HIV-positive and at-risk HIV-negative adults. Cancer Epidemiol Biomarkers Prev 21: 122-133.

28. Sigel K, Dubrow R, Silverberg M, Crothers K, Braithwaite S, et al. (2011) Cancer Screening in Patients Infected with HIV. Curr HIV/AIDS Rep 8: $142-152$.

29. Tyerman Z, Aboulafia DM (2012) Review of screening guidelines for non-AIDS-defining malignancies: Evoking issues in the era of highly active antiretroviral therapy. AIDS Rev 14: 3-16. 


\section{di \\ нита}

Journal of Anesthesia \& Clinical Care

Journal of Addiction \& Addictive Disorders

Advances in Microbiology Research

Advances in Industrial Biotechnology

Journal of Agronomy \& Agricultural Science

Journal of AIDS Clinical Research \& STDs

Journal of Alcoholism, Drug Abuse \& Substance Dependence

Journal of Allergy Disorders \& Therapy

Journal of Alternative, Complementary \& Integrative Medicine

Journal of Alzheimer's \& Neurodegenerative Diseases

Journal of Angiology \& Vascular Surgery

Journal of Animal Research \& Veterinary Science

Archives of Zoological Studies

Archives of Urology

Journal of Atmospheric \& Earth-Sciences

Journal of Aquaculture \& Fisheries

Journal of Biotech Research \& Biochemistry

Journal of Brain \& Neuroscience Research

Journal of Cancer Biology \& Treatment

Journal of Cardiology \& Neurocardiovascular Diseases

Journal of Cell Biology \& Cell Metabolism

Journal of Clinical Dermatology \& Therapy

Journal of Clinical Immunology \& Immunotherapy

Journal of Clinical Studies \& Medical Case Reports

Journal of Community Medicine \& Public Health Care

Current Trends: Medical \& Biological Engineering

Journal of Cytology \& Tissue Biology

Journal of Dentistry: Oral Health \& Cosmesis

Journal of Diabetes \& Metabolic Disorders

Journal of Dairy Research \& Technology

Journal of Emergency Medicine Trauma \& Surgical Care

Journal of Environmental Science: Current Research

Journal of Food Science \& Nutrition

Journal of Forensic, Legal \& Investigative Sciences

Journal of Gastroenterology \& Hepatology Research

Journal of Gerontology \& Geriatric Medicine
Journal of Genetics \& Genomic Sciences

Journal of Hematology, Blood Transfusion \& Disorders

Journal of Human Endocrinology

Journal of Hospice \& Palliative Medical Care

Journal of Internal Medicine \& Primary Healthcare

Journal of Infectious \& Non Infectious Diseases

Journal of Light \& Laser: Current Trends

Journal of Modern Chemical Sciences

Journal of Medicine: Study \& Research

Journal of Nanotechnology: Nanomedicine \& Nanobiotechnology

Journal of Neonatology \& Clinical Pediatrics

Journal of Nephrology \& Renal Therapy

Journal of Non Invasive Vascular Investigation

Journal of Nuclear Medicine, Radiology \& Radiation Therapy

Journal of Obesity \& Weight Loss

Journal of Orthopedic Research \& Physiotherapy

Journal of Otolaryngology, Head \& Neck Surgery

Journal of Protein Research \& Bioinformatics

Journal of Pathology Clinical \& Medical Research

Journal of Pharmacology, Pharmaceutics \& Pharmacovigilance

Journal of Physical Medicine, Rehabilitation \& Disabilities

Journal of Plant Science: Current Research

Journal of Psychiatry, Depression \& Anxiety

Journal of Pulmonary Medicine \& Respiratory Research

Journal of Practical \& Professional Nursing

Journal of Reproductive Medicine, Gynaecology \& Obstetrics

Journal of Stem Cells Research, Development \& Therapy

Journal of Surgery: Current Trends \& Innovations

Journal of Toxicology: Current Research

Journal of Translational Science and Research

Trends in Anatomy \& Physiology

Journal of Vaccines Research \& Vaccination

Journal of Virology \& Antivirals

Submit Your Manuscript: http://www.heraldopenaccess.us/Online-Submission.php 